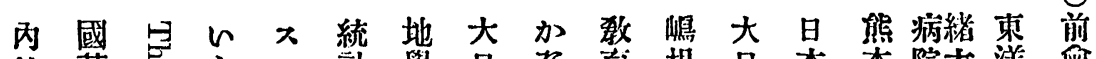

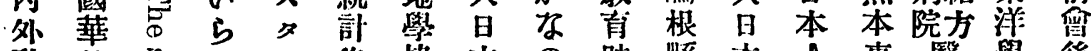

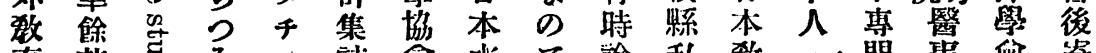

有芳总み

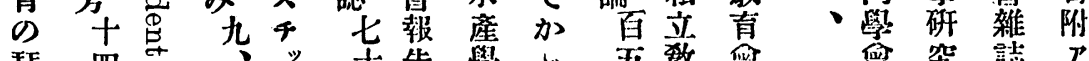

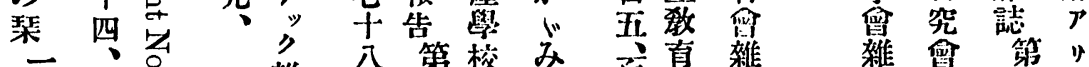

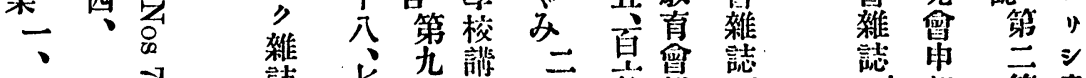

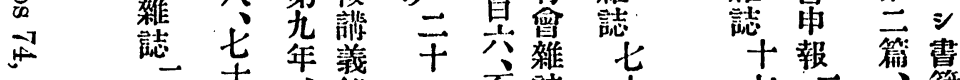

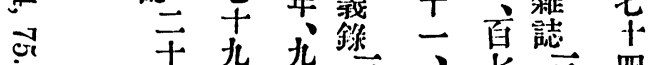

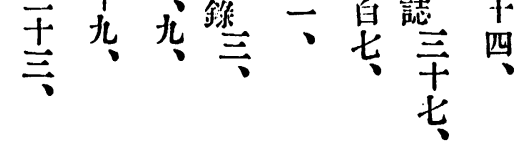

七 二四籍

以

脚

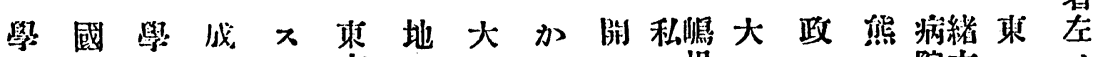
華衍”京昆な 根日本院方洋如

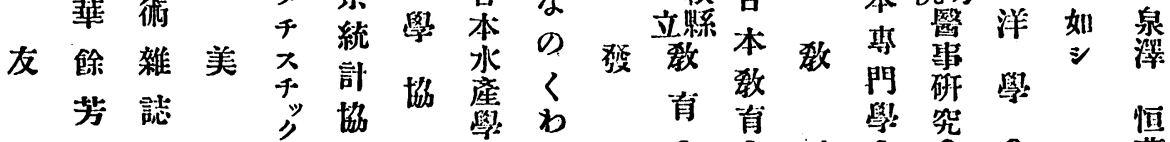

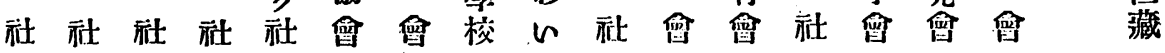


之八故决》晴八君 $\nu$ 先其 $三$ 常 $=v$, 出文君 $\Rightarrow$ 次兼坐入其御》㓩地 が 似何第子、文次說モ掛, 人 $\exists モ \forall \vec{\gamma}$ 就云 $\exists$ 中, $>$ 所 類 $\nu$ 搆書居 $、$ 山二父御々學 ル $*$ モ $レ$ 中見 $ラ$ 幣 $=$ 曾 物 $ス$ 記 $\exists$ 今 $シ$ 尤 $シ$ 氏 $、 1$ 似告

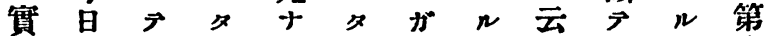

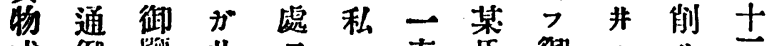

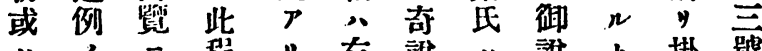

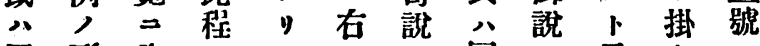

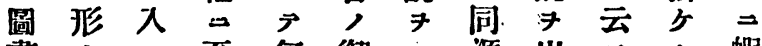
畵 $ン$ 至 何御》源出 $>1$ 蝦

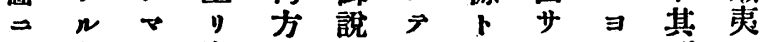
求御入漸卜卢、壬

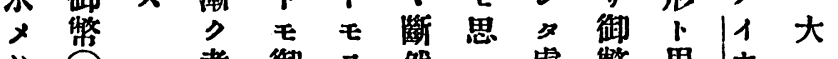
》若御 $\neq$ 然 $八$ 處幣用十


四付㨐見者申十削所1

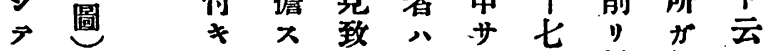
其 $7 \rightarrow n$ 至起 $x$ 號掛似》 侧取 シ 所 $\rightarrow$ 源 1 坪多 $\vec{モ}$

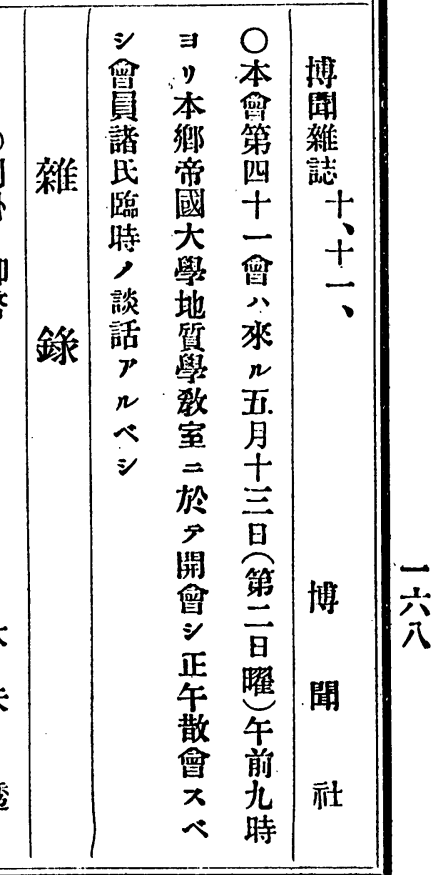




\section{月四年 一十二治 明}

邻

見云, n,

名條モル

几 延 $\Rightarrow$, 上

は喜大力上

¿ 武盤 $1 \overrightarrow{7}$

水条游究先

に工, 繁

の 察 紙 致 九。

海式三㘳十。

$5=$ 怗 $>$ 及

世藻內 オ

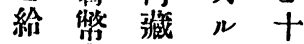

系帛察 = -

云条, 江,

䓃絹家圖

六死次中

方枚正籍=

ス避イ゚ノル較其モモ

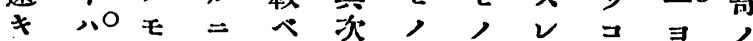

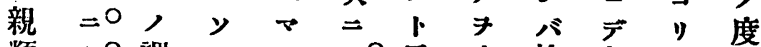
類 $x^{\circ}$ 謂 $v \times 10$ 云次格其 +0 = ダ メが 上兄

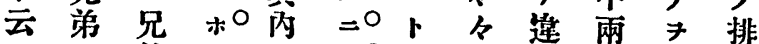

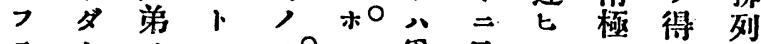

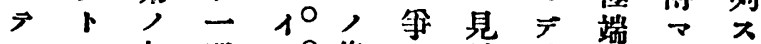
モ大如所

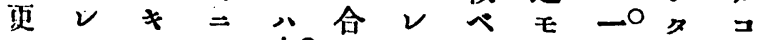

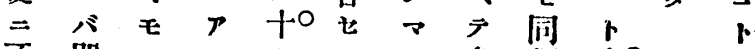
不即, $上$ 七參類十。 常千卜以

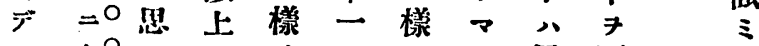

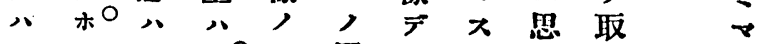

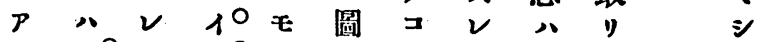
ル

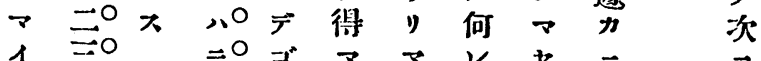
1. 四

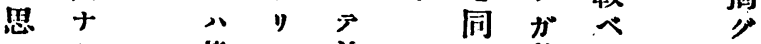
$\therefore N$ 皆 $\rightarrow$ 前 血 $;$ V、同 $\pi$ 後統間甚圆

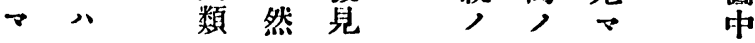

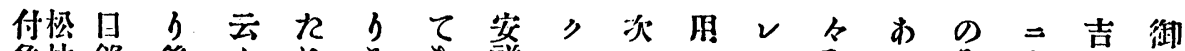
㷛枝録後々 犯々

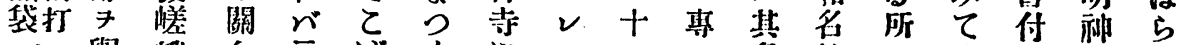

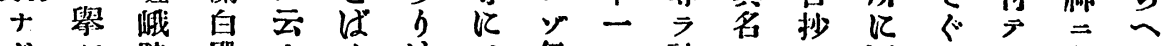

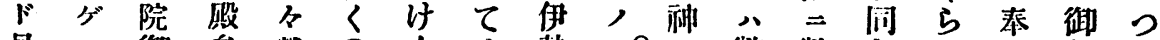



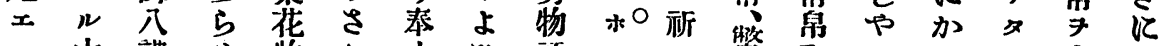



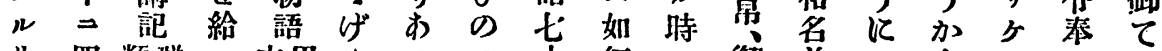




グ 三三銀の をた

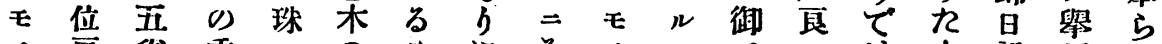



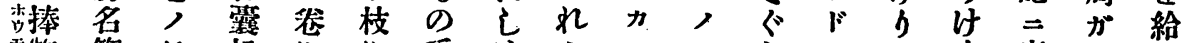



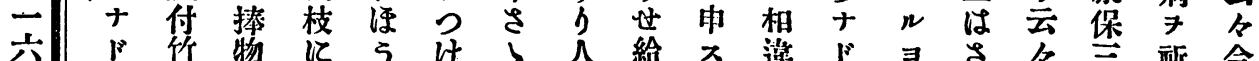


フ右有姇方 堂ば

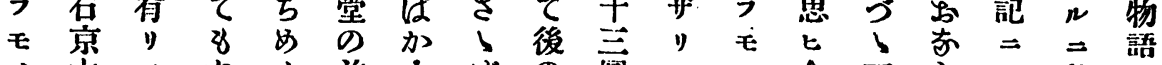



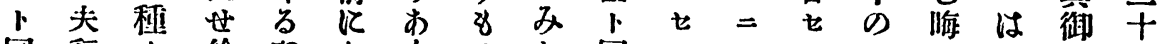
同行冬給な た

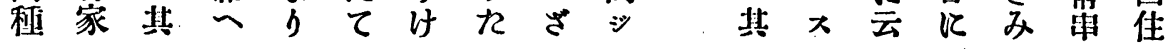


號六十二第誌雜曾學類人京束






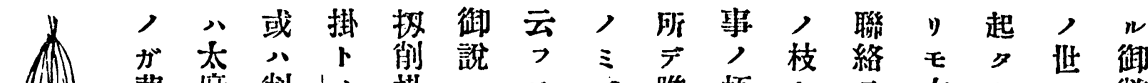

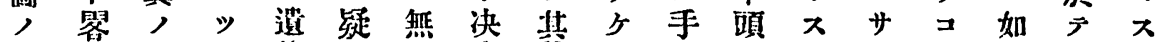
如

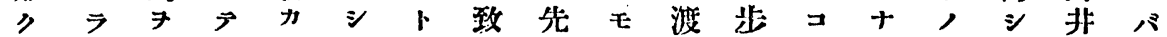



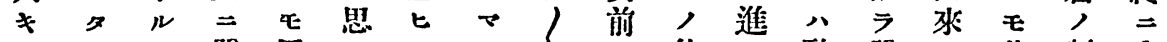

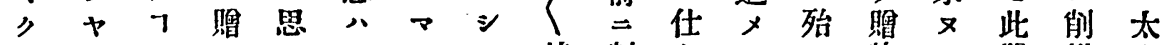
七学》分

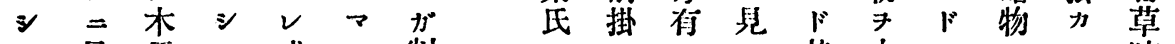

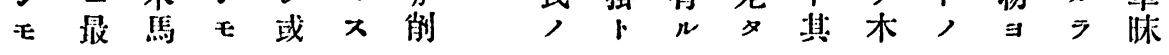

社遙赤儿利们 十邦心栐, 八八士



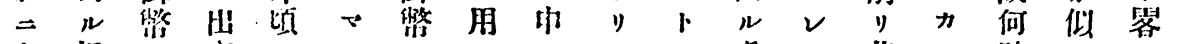

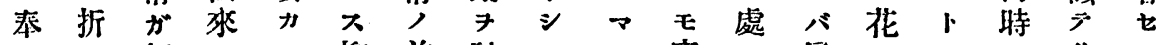

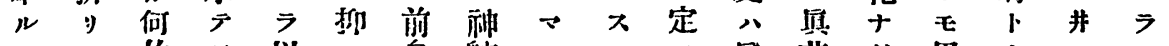



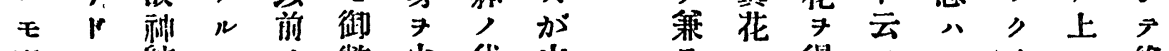

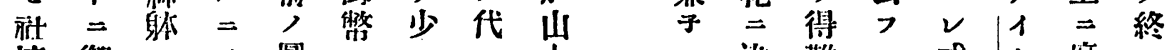
墥御 $=\vec{\gamma}$ 圆节

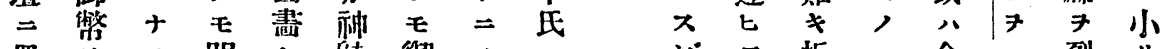

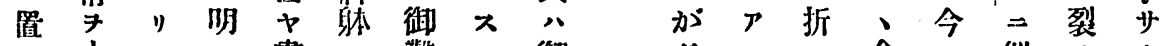

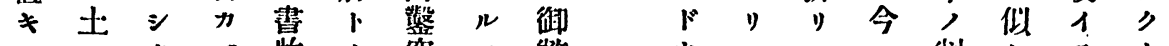

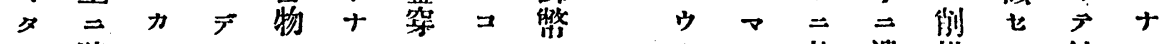
》建卜 ゴ

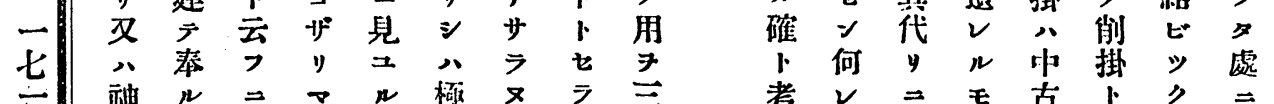

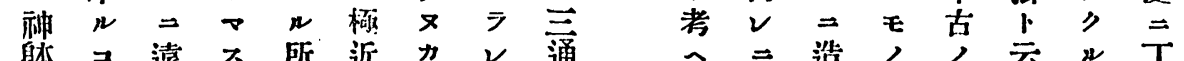

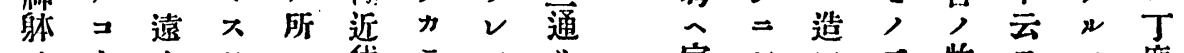
人 無

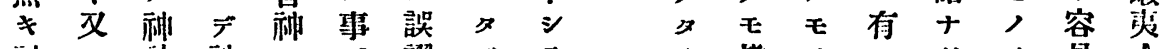



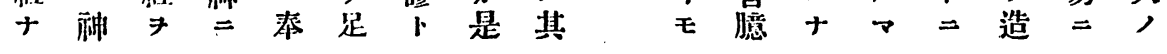


號六十二第誌雑會學類入京東

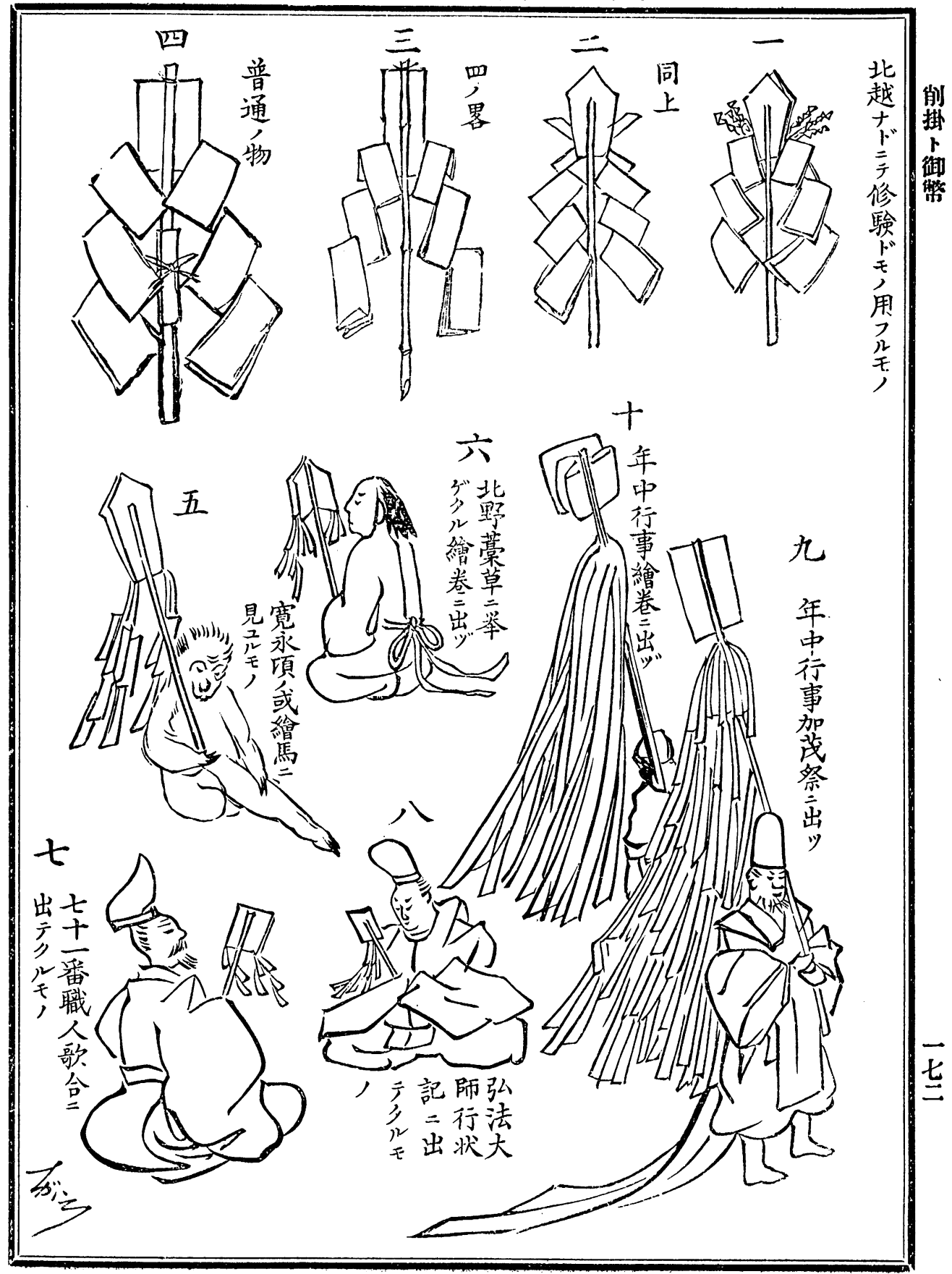




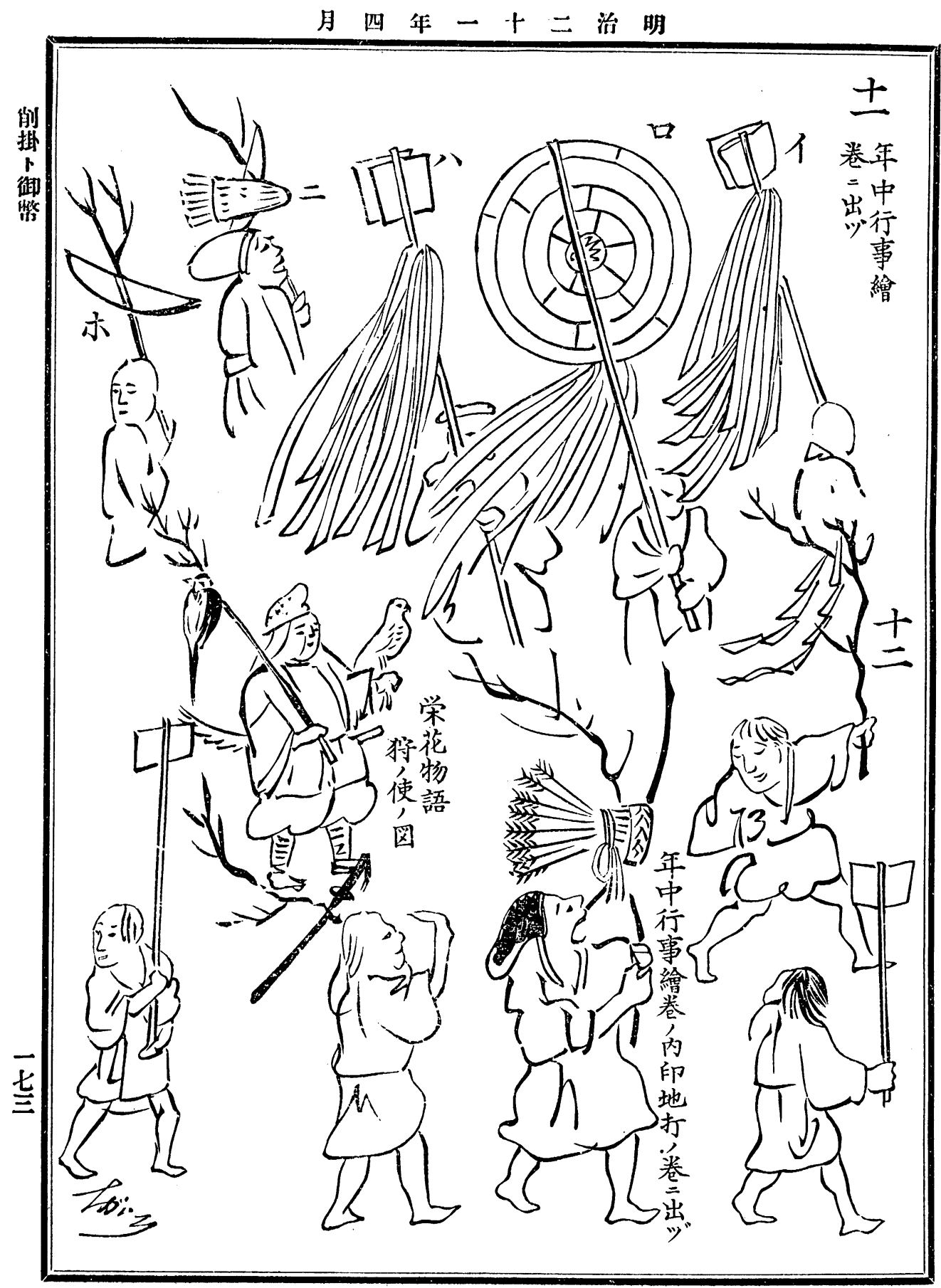






